\title{
The Communication and Its Influence on the Effectiveness of the Organization
}

\author{
Altin Uka \\ Tirana European University, \\ Tirana, Albania \\ e-mail: altiuka@gmail.com
}

Doi:10.5901/mjss.2014.v5n2p165

\begin{abstract}
In its universalization of the work of management, communication presents an unquestionable importance and an issue, in which managers are focused and engaged in a continuous process of improvement. Communication appears with a key role towards organizational cultures. An effective interpersonal communication, is accompanying by a better collective action, especially in terms of achieving the organizational goals. In synchronous and complementarily with the execution of the strategy, such as organizational culture, it is in full support of achieving the organization's objectives, specifically influencing in the effectiveness of the organization. Also communication is seen in continuity, as a key component in the execution of strategy. Focusing on the active interconnection that communication has with the organizational culture and organizational strategy execution, accompanied with relevant improvements in communication, the incentives leading to an improvement, organization effectiveness.
\end{abstract}

Keywords: communication, effectiveness, strategy, objective, goal, organisational culture

\section{Introduction}

Nowadays, communication more and more takes a special importance, appearing as a universal tool for management and managers in every organization. Everything and everyone in the organization is based and operates in continuous manner on the basis of communication. Without communication it is hardly to believe organizing the work and even more to talk about one of its effective management.

In this multidimensional aspect of the importance that communication takes in the organization, a special place occupies the dimension and its inalienable role as a key component, in the successfully implement of the organizational strategy, leading to a high efficiency of organization.

A satisfactory skill, in terms of interpersonal communication, a better communication leads to a better collective action and effective especially towards a shared goal. All this leads to a higher efficiency of the organization.

On the other hand, it is worth mentioning the importance and direct impact of organizational culture as a permanent support for the fulfillment of the vision, mission and achieving the organization's objectives. Organizational culture and strategy, in particular its execution, always appear synchronous and complementarily with each other. On The Other Hand Organizational Culture Itself encounters a significant impact on the Organization Effectiveness. At this point is also seen the respective contribution of communication, because the organizational culture is expressed through Communication.

Also the communication appears as a key component in the properly direction of executing the strategy, in terms of its impact on the increasingly involvement of the organization's employees in the process of executing the strategy, as well as achieving the goals of employees that go toward the organization's goals.

Effectiveness and finding appropriate routes in this direction is a constant issue for Energy Regulatory Authority (ERA). The paper takes into consideration a very important factor of Management as is Organizational Culture., An important Role in determining the Organization, its complementary related with its Strategy and Execution, which both, in terms of a better performance, would lead to a higher level of Effectiveness of the Organization.

Here it is worth mentioning the position and active interconnection that the Communication has with Organizational Culture and Organization Strategy, and its impact on them. An improvement in Techniques and Methods of Communication will certainly result in improvement in the Effectiveness of the Organization. 
Fig. 1. The Communication and its effectiveness in Organization

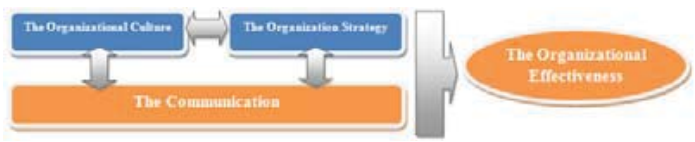

This paper will explore, which is the current status of Organizational Culture in ERA, where the institution "fails, the identification of the currently relevant issues and what could be improved, especially looking in direction of improving the Effectiveness of the Organization

Analysing the Mission Statement of ERA, Tracking the Execution of the Strategy and the Aim to accomplish the Goals of the Organization, constitute important objectives of this paper. These are closely related with the Organizational Culture through Communication improvement, which runs proportionally with them, identifying that an important improvement is associated with an improvement in terms of the Effectiveness of the Organization itself.

Own importance that takes the Communication in treatment in this paper, will ask what is the "State" of the Communication in ERA, with particular emphasis on possible improvements to it

\section{Literature Review}

In fact, communication takes a universal aspect in the work of management and manager in any organization. Everything and everyone in the organization, is linked to a network of decisions and information, which are in an uninterrupted interaction and totally interdependent on each other. At the end this whole system is based on it - communication: "...everything that makes a manager involves communication. Not some things, but everything! A manager can not formulate strategy, or make a decision without information. That information should be communicated. Once a decision is made, communication occurs again. Otherwise, no one will know what decision is taken. The best idea, suggestion with creative or more subtle plan may not take shape without communication" (Robbins/DeCenzo, 2011).

All Messages and Communications should reflect the Strategic Objectives. In an Organization each Interpersonal Relationship exists within a complex network of interrelated relationship, resulting with the ability to communicate interpersonally becomes a foundational skill for virtually any other organizational activity. Toward a shared goal, a better communication brings more effective collective actions.. It is important to be emphasized that the Goals decided need to be communicated internally and externally, influencing the Effectiveness of the Organization itself. Interpersonal Communication, Interpersonal Skills affect the Effectiveness of the Organization: "Now, Fortune 500 companies name strong interpersonal, communicating and team skills as the most important criteria for success in management positions" (Buckley, Peach \& Weizel, 1989; Kane, 1993), and "employers consistently name interpersonal communication skills as crucial for success on the job" (Maes, Weldy \& Icenogle, 1977).

Following the significance of communication for managers, it comes out and gets a first hand importance, in terms of successful implementation of the strategy: "Managers must have excellent communication skills to ensure strategy execution. The involvement of senior management in communicating strategy is an especially important factor in employees' understanding of organizational strategy and how their jobs contribute, according to Angela Sinickas, president of international communication consultancy Sinickas Communications, Inc." (American Management Association, 2007).

A determinant factor in the Management of the Organization is the Organizational Culture, which in its various definitions equate it with the essence of the Organization: "A company's culture is important because it influences the organization's actions and approaches to conducting business - in a very real sense, the culture is the company's "operating system" or organisational DNA" " (Arthur A.Thomson, Jr.; AJ Strickland III; John E. Gamble ). Of course if you're talking about a "Good Organizational Culture" is taken into consideration especially the fact that it reinforces or supports the Strategy, Vision, Mission and Objectives of the Organization. After the development of a Strategic Plan, realistic challenges still remain important in its Execution and achievement of Objectives. Organizational Culture is intended that the organization be in resonance with the Strategy, particularly its implementation, thereby providing a higher level of Organization Effectiveness.

Indeed, Organizational Culture and Strategy synchronize and are seen as complementary to each other: "One answer I found in recent research was refreshingly simple and almost so obvious that it is easily overlooked: align your strategy with your culture" (Mandy Carley, 2010) and "By connecting cultural beliefs with our corporate Vision and day to day execution, Culture Connections helps to re-energize West Jetters and fuel the Culture" (Financial Times.). On the 
other hand Organizational Culture itself has a significant impact on the Execution of Strategy. A high performance in Strategy Implementation, and achievement of the Objectives, means an Effective Organization. Organizational Culture is expressed through Communication and content of these Communications should reflect the specific Cultural Value, which highlights the importance of Communication in the Effectiveness of the Organization itself.

The involvement of every employee in the process of implementing the strategy, not only leads to a better recognition from them, but also in a process of awareness for their work, seeing it closely associated with the implementation of the organization strategy. All this leads to increase the organizational effectiveness. "The involvement of members of the organization in the strategy development process or the planning of the strategic change is also, in itself, a means of communication and can be very effective" (Gerry Johnson, Kevan Scholes, Richard Whittington, 2006).Depending On the good level of communication, is easily to see the employees performance toward achieving the goals, thus aiming an increasement in the performance of their work, as well as proper handling in the various obstacles that arise during the process of change. Positive changes in both these directions, lead to increase the performance of the organization. "How well you perform your task to meet your goal will depend upon how well you design your initial communication, how rigorously you follow up, and how successful you are at responding to the concerns of those who have reservations about adopting a new process." (Lori Harvill Moore, 2013).

While the focus and the importance of communication as a key in the strategy execution, occupies an important role in studies and practical applications of our times: "The importance of communication as a best practice to execute strategy is worth noting. Earlier research made communication a peripheral concern, focusing instead on issues such as organizational structure and processes such as reward systems and resource allocation (Schultz, Hatch, and Larsen 2000). More recent literature suggests, however, that communication is key to proper execution" (American Management Association, 2007). The further attention and elaboration of communication, in terms of strategy implementation, is an important component in the overall configuration issue, to achieve the strategic objectives of the organization and its effectiveness.

From the above definitions is noticed the mutual interactions between Organizational Culture, Strategy the Role and the Weight that has Communication with them. The Communication in the Organization appears in an important dimension that has a direct connection with the above two components, influencing and being influenced by them, and what gets a special weight is its influence on the Effectiveness of the Organization. To be taken into consideration correlations as above and in particular situations the Communication needs continuous improvement in the organization.

\section{Method}

The methodology used is mainly based on a Written Survey where the questionnaire used is based exactly to assessment directions according to the Organizational Culture, Organization Strategy and the Communication. Also has been established a face-to-face Interview with two employees of the ERA, and also through an observation, which consists in participation in a formal Meeting.

ERA as the organization has a total number of 25 employees, while the questionnaire was distributed to and completed by his 17 employees.

Through formulated based journalist question, according to this assessment:

1 = strongly disagree; 2 = do not agree; 3 = neutral; 4 = agree; 5 = totally agree,

Individual involved in this Survey, responded to various questions, according to the above directions, making assessment according to him, what is at issue relevant under their perspective.

Fig. 2. The Methodology

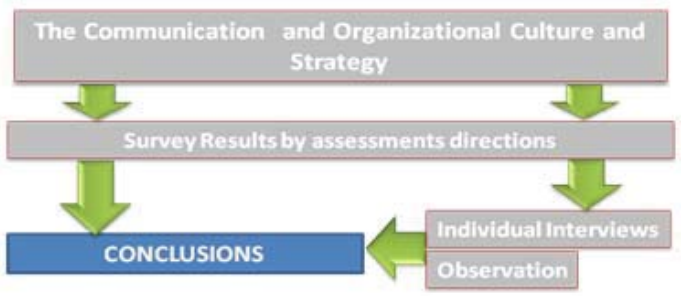




\section{Results}

Following the result graphically:

Fig. 3. Graph of results of Questionnaire

1 The organization keeps close its Mission

2 Communication contains and reflects the specific values of organizational culture

3 You meet regularly with the group you work and communicate with them by taking appropriate feedback

4 All staff involved and engaged in the implementation of the organization's mission

5 All staff involved and sets the value for the organization

6 Staff is encouraged and believes in the organization and what it makes

7 In organization there is truth, which appears in communication

8 Staff allowed to have access to relevant decision-making process

$9 \quad$ Management practices are transparent

10 Decisions are made in a fair and consistent manner

11 The organization develops process that ensures that the communication is working and updated

12 Employees know what is happening and know how to provide explanations about important issues facing organizations

13 Internal communication has succeeded in providing proper information and necessary

14 Your actions go towards the general objectives of the organization

15 Collective action goes towards a common goal

16 Interpersonal communication is important in the organization's activities

17 Interpersonal skills enable an organization to be effective

18 Internal communication, external, verbal and non-verbal, conscious or unconscious of, is vital in the organization

19 Employees are optimistic that the organization keeps close to its promises, especially those that are published visible

20

There is no an inconsistency between the way that the public presentation of the organization and how employees perceive its value

Most of the respondents, referring to the above displayed graph, responded at around $70 \%$ with "Agree", $20 \%$ of them are "Totally Agree", and the rest are around 10\% "Neutral" in their appreciation of the respective questions raised.

At "Neutral" assertion, remains fixed: "In the organization there is truth, which appears in communication", while there is a slight tendency, as the attitude towards "agree": "Staff is encouraged and believes in the organization and what it makes","

At "Totally Agree" assertion, remain fixed: "The organization keeps close its Mission", "Internal communication, external, verbal and non-verbal, conscious or unconscious of, is vital in the organization", "Your actions go towards the general objectives of the organization", meanwhile, displayed a nuance in attitude towards "agree" on: "There is no an inconsistency between the way that the public presentation of the organization and how employees perceive its value".

At "Agree" assertion, remain fixed: "All staff involved and sets the value for the organization", "Decisions are made in a fair and consistent manner", "Internal communication has succeeded in providing proper information and necessary", while seen as an approach goes tendency to "strongly agree" to: "Communication contains and reflects the specific values of organizational culture", "Employees know what is happening and know how to provide explanations about important issues facing organizations", "Collective action goes towards a common goal", "Interpersonal communication is important in the organization's activities", "Interpersonal skills enable an organization to be effective", "Employees are optimistic that the organization keeps close to its promises, especially those that are published visible. While tinge to display a trend to "neutral" claims as : "You meet regularly with the group you work and communicate with them by taking appropriate feedback", "All staff involved and engaged in the implementation of the organization's mission", "Staff allowed to have access to relevant decision-making process", "Management practices are transparent".

The results of two Interviews, given by the Department Director and a an Specialist, have almost great similarities to their answers. . They appreciate the Communication as an important, concept of their work, a better "Network" of Human and Technologies in the Organization, has a direct effect on improving the Concepts and Values of the Organization and also improve the Strategy, making possible higher Effectiveness on the Organization in general,. They 
generally respond correct to the evolution of the issues raised in the Questionnaire, but of course for some questions they stand to a relativity scale in their responses. However, once identified apparent problems, in the Questionnaire and issues related to the "Truth" and the staff regarding "Being encouraged" and "Believes" in Organization, verbal responses show real difficulties encountered with these elements of Communication.

Observation made during a routine Meeting, identifies and generally is consistent with the Findings made in the above two quantitative and qualitative evaluations.

\section{Conclusions and Recommendations}

$\S \quad$ The employees of the organization immediately need a "Building Trust" and "Encourage Staff" in order to believe in the Organization and what it does. An effective Communication and a higher transparency will lead significantly to these improvements;

$\S$ Communication should reflect more specific values of the Organization, Culture, which need improvement in some elements;

$\S$ Work in groups, and Communication can be further improved and in this case more working for improving Interpersonal Communication;

$\S$ The Organization, through improved Communication, should be committed toward; an effective involvement in implementation of its Mission;

$\S$ Through Inclusiveness and Improvement of Tools and Technology of Communication in the Organization, they will have a growing degree in Communication that means staff can set the value for the Organization;

$\S$ Organizations should increase a higher level of Access for staff, in the Decision-Making process;

$\S$ Through further improvements of the Communication, Management Practices could be more transparent;

$\S$ Through a wide Transparency, a special place must be occupied by the increase of the Communication level and Decision-Making should be more "Fair" and more Consistent;

$\S$ By improving the Communication, employees can have more information about what happens in the Organization. This means to be more involved with different issues and be able to provide explanations for even the most important ones in the Organization

$\S$ There is still to be done for improving the Communication, which will affect the direction of providing appropriate and necessary internal information,

$\S$ It is required a better Coordination and Communication, so that individual actions, converge on a common Collective action towards a common goal;

$\S \quad$ A higher and right information related to Strategy, Organizational Culture and Communication issues appears as a priority of the Organisation,. In this regard, it is required that the employees should be trained particularly for Communication Issues, seeing its improvement as a progress in general for the welfare of the Organization, towards an increment of its Effectiveness

\section{References}

Kevin Ruck : "The importance of internal communication in organizational culture", February 10, 2013;

American Management Association (AMA) : "The Keys to strategy Execution", 2007;

University Salford Manchester: "The role of culture on communication behavior in public/private organization: a review literature", 2009;

Robbins/DeCENZO : "Bazat e Menaxhimit. Koncepte dhe aplikime themelore", 2011 UET Press;

Johnson, Scholes, Whittington : "Exploring Corporate Strategy", 2006;

Investors in People : "Culture and Communication", 2013;

Mandy Carley : "Can organizational culture make your communication clearer?", March 10, 2011;

Felicity Zadro : "Managing Organizational Culture through communication", 2013;

Answers : "What is the relationship between culture and communication?", 2013;

Marty Parker : "Communicating Corporate Culture", February 27, 2012;

Dale Cyphert : "Culture and Communication in Organization", 2007;

Marcus Paine, eHow Contributor : "Factors That Influence Interpersonal Communication";

eNotes : "What are the barriers of communication in an organization", March 27, 2009; Chestar Barnard : "Organizational Psychology";

Melanie R. Salom : "Interpersonal Communication in the Workplace: Manager-Subordinate Relationships", November 12, 2009;

Andri Koxhaj, Florian Tomini : "Management of Communication", Aprill 2006;

Andri Koxhaj: "Aftesite e Menaxhimit", 2006;

Johnny Mnemonic : "Organizational Communication"; 
Arthur A.Thomson, Jr.; AJ Strickland III; John E. Gamble : "Crafting and Executing Strategy";

Gerry Johnson, Kevan Scholes, Richard Whittington : "Exploring Corporate Strategy", 2006; 